\title{
Heavy incense burning in temples promotes exposure risk from airborne PMs and carcinogenic PAHs
}

\author{
Kuo-Chih Chiang, Chung-Min Liao * \\ Ecotoxicological Modeling Center, Department of Bioenvironmental Systems Engineering, National Taiwan University, Taipei, Taiwan 10617 ROC
}

Received 2 January 2006; received in revised form 13 June 2006; accepted 6 August 2006

Available online 18 September 2006

\begin{abstract}
We present the mechanistic-based exposure and risk models, appraised with reported empirical data, to assess how the human exposure to airborne particulate matters (PMs) and carcinogenic polycyclic aromatic hydrocarbons (PAHs) during heavy incense burning episodes in temples. The models integrate size-dependent PM levels inside a temple from a published exploratory study associated with a human expiratory tract (HRT) model taking into account the personal exposure levels and size distributions in the HRT. The probabilistic exposure profiles of total-PAH levels inside a temple and internal PAHs doses are characterized by a physiologically based pharmacokinetic (PBPK) model with the reconstructed dose-response relationships based on an empirical three-parameter Hill equation model, describing PAHs toxicity for DNA adducts formation and lung tumor incidence responses in human white blood cells and lung. Results show that the alveolar-interstitial (AI) region has a lower mass median diameter $(0.29 \mu \mathrm{m})$ than that in extrathoracic $\left(\mathrm{ET}_{1}, 0.37 \mu \mathrm{m}\right)$, brochial $(\mathrm{BB}, 0.36 \mu \mathrm{m})$ and bronchiolar $(\mathrm{bb}, 0.32 \mu \mathrm{m})$ regions. The $50 \%$ probability (risk $=0.5)$ of exceeding the DNA adducts frequency $\left(\mathrm{DA}_{\mathrm{f}}\right)$ ratio of $1.28(95 \% \mathrm{CI}$ : $0.55-2.40)$ and $1.78(95 \%$ CI: $0.84-$ 2.95 ) for external exposure of $\mathrm{B}[a] \mathrm{P}$ and $\mathrm{B}[a] \mathrm{P}_{\text {eq }}$, respectively. The $10 \%$ (risk $=0.1$ ) probability or more of human affected by lung tumor is approximately $7.62 \times 10^{-5} \%\left(95 \%\right.$ CI: $\left.3.39 \times 10^{-5}-1.71 \times 10^{-4} \%\right)$ and $3.87 \times 10^{-4} \%\left(95 \%\right.$ CI: $\left.1.72 \times 10^{-4}-8.69 \times 10^{-4} \%\right)$ for internal exposure of $\mathrm{B}[a] \mathrm{P}$ and $\mathrm{B}[a] \mathrm{P}_{\text {eq }}$, respectively. Our results implicate that exposure to smoke emitted from heavy incense burning may promote lung cancer risk. Our study provides a quantitative basis for objective risk prediction of heavy incense burning exposure in temples and for evaluating the effectiveness of management.
\end{abstract}

(C) 2006 Elsevier B.V. All rights reserved.

Keywords: Temple; Incense burning; Particulate matters; Polycyclic aromatic hydrocarbons; HRT model; PBPK model; Risk assessment

\section{Introduction}

Burning incense to worship deities is a daily religious ritual in most Buddhist and Taoist temples in Taiwan. Approximately 1.5 million frequent visitors visit more than 14,500 temples across the Taiwan region and subject to burn incense inside the temples (http://www.

\footnotetext{
* Corresponding author. Tel.: +88622363 4512; fax: +88622362 6433

E-mail address: cmliao@ntu.edu.tw (C.-M. Liao).
}

moi.gov.tw/stat/). Incense and joss paper burning were found to be the significant sources of large amount of particulate, heavy metals and gaseous pollutants (Ho and Yu, 2002; Lin et al., 2002; Fang et al., 2003; Lung et al., 2003; Lee and Wang, 2004; Chen, 2005; Chuang, 2005; Yang et al., 2005). Due to the nature of its long, slow and incomplete combustion process, this religious practice produces non-stop heavy smoke. Some temple workers exposed to smoke emitted from incense burning have been demonstrated that they increase the potential risk 
for the development of acute irritative symptoms, including nose and throat irritation (Ho et al., 2005). With the rising of environmental and health awareness, the public health risk assessments are paying more attention to the religious practice in temples.

Recently, more studies have focused on airborne particulate matters (PMs) and carcinogenic polycyclic aromatic hydrocarbons (PAHs) during incense burning in Taiwanese temples (Lin et al., 2002; Lung et al., 2003; Chuang, 2005). It was found that $\mathrm{PM}_{10}$ concentrations was $155.1 \pm 41.5 \mu \mathrm{g} \mathrm{m}^{-3}$ and $\mathrm{PM}_{1} / \mathrm{PM}_{10}$ ratios were estimated to be $81.2 \pm 5.3 \%$, indicating that fine PMs constitute the majority of indoor suspended particulate in the temples (Chuang, 2005). Lin et al. (2002) have also found that the composition of PAHs emitted from incense burning varies greatly due to differences in the raw materials used in incense making. Lung et al. (2003) indicated that contribution of incense burning to indoor exposure concentrations of particle-bound PAHs ranged from 88 to $450 \mathrm{ng} \mathrm{m}^{-3}$. Lin et al. (2002) demonstrated that indoor and outdoor mean total PAHs in a selected temple were measured to be 6258 and $231 \mathrm{ng} \mathrm{m}^{-3}$, respectively, in that median values for indoor/outdoor ratios of individual PAHs ranged from 5.7 to 387.9, suggesting that temple is a significant PAH source.

Table 1

Potency equivalency factor (PEF) for PAHs relative to $\mathrm{B}[a] \mathrm{P}$ used in this study (Nisbet and LaGoy, 1992)

\begin{tabular}{|c|c|}
\hline Name with abbreviation & PEF \\
\hline \multicolumn{2}{|l|}{ Reference } \\
\hline Benzo $[a]$ pyrene $(\mathrm{B}[a] \mathrm{P})$ & 1 \\
\hline \multicolumn{2}{|l|}{$P A H s$} \\
\hline Acenaphthene (Acp) & 0.001 \\
\hline Acenaphthylene (AcPy) & 0.001 \\
\hline Anthracene (Ant) & 0.01 \\
\hline Benzo $[a]$ anthracene $(\mathrm{B}[a] \mathrm{A})$ & 0.1 \\
\hline Benzo $[b]$ chrycene $(\mathrm{B}[b] \mathrm{C})$ & NA \\
\hline Benzo $[b]$ fluoranthene $(\mathrm{B}[b] \mathrm{FT})$ & 0.1 \\
\hline Benzo $[k]$ fluoranthene $(\mathrm{B}[k] \mathrm{FT})$ & 0.1 \\
\hline Benzo $[e]$ pyrene $(\mathrm{B}[e] \mathrm{P})$ & $0.01^{\mathrm{a}}$ \\
\hline Benzo $[g, h . i]$ perylene $(\mathrm{B}[g, h . i] \mathrm{P})$ & 0.01 \\
\hline Chrysene (CHR) & 0.01 \\
\hline Coronene (COR) & $0.001^{\mathrm{a}}$ \\
\hline Cyclopenta $[c, d]$ pyrene $(\mathrm{C}[c, d] \mathrm{P})$ & $0.1^{\mathrm{a}}$ \\
\hline Dibenzo $[a, h]$ anthracene $(\mathrm{DB}[a, h] \mathrm{A})$ & $1^{\mathrm{a}}$ \\
\hline Fluoranthene (FL) & 0.001 \\
\hline Fluorene (Flu) & 0.001 \\
\hline Indeno $[1,2,3-c, d]$ pyrene $(\operatorname{In}[c, d] \mathrm{P})$ & 0.1 \\
\hline Naphthalene (Nap) & 0.001 \\
\hline Perylene (PER) & $0.001^{\mathrm{a}}$ \\
\hline Phenanthrene (PA) & 0.001 \\
\hline Pyrene (Pyr) & 0.001 \\
\hline
\end{tabular}

${ }^{\text {a }}$ Value adopted from Malcom and Dobson (1994).

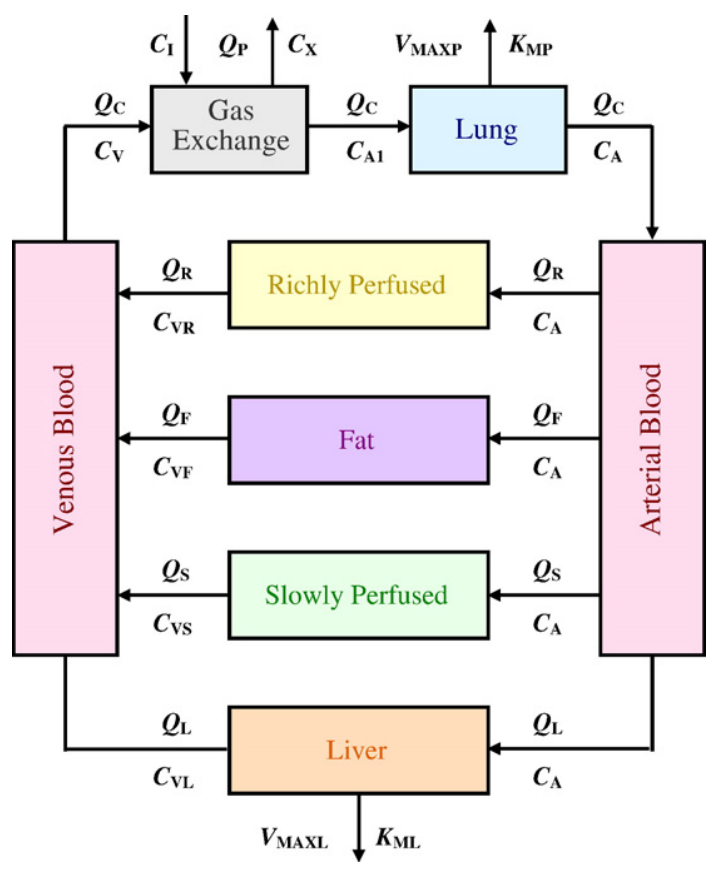

Fig. 1. A schematic description of the PBPK model structure for human exposed to carcinogenic PAHs by inhalation, showing the regional tissues absorption, distribution, metabolism and excretion processes.

Numerous studies related to inhalation epidemiology have shown a positive association between ambient PM concentrations and adverse health effects such as increased respiratory symptoms, decreased lung function, increased lung cancer incidence, cardiovascular mortality, and accelerated atherosclerosis and vascular inflammation (Pope et al., 2002, 2004; Sun et al., 2005). In an animal model, Sun et al. (2005) concluded that long-term exposure to low concentration of $\mathrm{PM}_{2.5}$ altered vasomotor tone, induced vascular inflammation and potentiated atherosclerosis. Boffetta et al. (1997) demonstrated that human cancer causes of skin, lungs and bladder have always been associated with PAHs. Armstrong et al. (2004) pointed out that the relationship between cancer and the environment is largely conditioned by investigations involving $\mathrm{PAH}$ exposures. PAHs have been associated with elevated levels of DNA adducts (PAH-DNA adducts) and $p 53$ mutations in persons who smoke or are exposed to PAH in the workplace and ambient air (Smith et al., 2000; Peluso et al., 2001). Li et al. (2001) indicated that PAH-DNA adducts formed by the carcinogen $\mathrm{B}[a] \mathrm{P}$ diol epoxide $(\mathrm{B}[a] \mathrm{PDE})$ have been linked to an increased risk of lung cancer.

The development of mechanistic dosimetry models is an important step in understanding exposure-dose-response relationships for ambient PMs and toxic environmental chemicals, which can provide a valuable tool to assess human health risks. Numerous mathematical 
Table 2

Mathematical expressions of the human PBPK model ${ }^{\mathrm{a}}$

Gas exchange compartment

$C_{\mathrm{A} 1}=\frac{Q_{\mathrm{C}} C_{\mathrm{V}}+Q_{\mathrm{P}} C_{\mathrm{I}}}{Q_{\mathrm{C}}+Q_{\mathrm{P}} / P_{\mathrm{B}}}$

$(T 1-1)$

$C_{\mathrm{A}}=C_{\mathrm{P}} / P_{\mathrm{P}}$

Lung compartment (where metabolism occurs)

$V_{\mathrm{P}} \frac{\mathrm{d} C_{\mathrm{P}}}{\mathrm{d} t}=Q_{\mathrm{C}}\left(C_{\mathrm{A} 1}-C_{\mathrm{A}}\right)-\frac{V_{\mathrm{MAXP}} C_{\mathrm{A}}}{K_{\mathrm{MP}}+C_{\mathrm{A}}}$

Liver compartment (where metabolism occurs)

$V_{\mathrm{L}} \frac{\mathrm{d} C_{\mathrm{L}}}{\mathrm{d} t}=Q_{\mathrm{L}}\left(C_{\mathrm{A}}-C_{\mathrm{VL}}\right)-\frac{V_{\mathrm{MAXP}} C_{\mathrm{VL}}}{K_{\mathrm{ML}}+C_{\mathrm{VL}}}$

Other compartment

$V_{i} \frac{\mathrm{d} C_{i}}{\mathrm{~d} t}=Q_{i}\left(C_{\mathrm{A}}-C_{\mathrm{V} i}\right)$

$(T 1-5)$

Venous return

$C_{\mathrm{V}}=\frac{Q_{\mathrm{R}} C_{\mathrm{VR}}+Q_{\mathrm{F}} C_{\mathrm{VF}}+Q_{\mathrm{S}} C_{\mathrm{VS}}+Q_{\mathrm{L}} C_{\mathrm{VL}}}{Q_{\mathrm{C}}}$

$(T 1-6)$

$C_{\mathrm{V} i}=C_{i} / P_{i}$

$(T 1-7)$

${ }^{\mathrm{a}} C_{\mathrm{A} 1}$ is the concentration in blood leaving gas exchange compartment; $C_{\mathrm{A}}$ is the arterial blood concentration; $C_{\mathrm{I}}$ is the inhaled air concentration; $C_{\mathrm{P}}$ is the concentration in lung; $C_{\mathrm{L}}$ is the concentration in liver; $C_{\mathrm{VL}}$ is the concentration in venous blood leaving liver; $C_{i}$ is the concentration in tissues $i$ (richly perfused, fat and slowly perfused); $C_{\mathrm{V} i}$ is the concentration in venous blood leaving the tissues $i ; Q_{\mathrm{P}}$ is alveolar ventilation rate; $Q_{\mathrm{C}}$ is cardiac output; $Q_{\mathrm{L}}$ is the blood flow rate to liver; $Q_{i}$ is the blood flow rate to tissue $i ; P_{\mathrm{B}}$ is the blood/air partition coefficient; $P_{\mathrm{P}}$ is the lung/blood partition coefficient; $P_{\mathrm{L}}$ is the liver/blood partition coefficient; $P_{i}$ is the partition coefficient to tissue $i ; V_{\mathrm{P}}$ is the lung volume; $V_{\mathrm{L}}$ is the liver volume; $V_{i}$ is the tissue $i$ volume; $V_{\text {MAXP }}$ is the maximum metabolism velocity in lung; $V_{\mathrm{MAXL}}$ is the maximum metabolism velocity in liver; $K_{\mathrm{MP}}$ is the Michaelis constant of lung; $K_{\mathrm{ML}}$ is the Michaelis constant of liver.

models for predicting PM deposition and organic chemicals distribution in human respiratory tract (HRT) and other tissues have been developed in a decade (ICRP, 1994; Lazaridis et al., 2001; Chen et al., 2004; Dennison et al., 2004; Clewell et al., 2005; Liao and Luo, 2005). Chen et al. (2004) and Liao and Luo (2005) developed a complete and realistic PM exposure model for HRT containing airflow dynamic, physiological, lung morphological and dose cumulated submodels. Dennison et al. (2004) and Clewell et al. (2005) used physiologically based pharmacokinetic (PBPK) models to describe the absorption, distribution, metabolism and excretion of individual chemical (perchloroethylene) and chemical
Table 3

Physiological and biochemical parameters used in the human PBPK model

\begin{tabular}{lc}
\hline Parameters & \multicolumn{1}{c}{ Human } \\
\hline Body weight $(\mathrm{kg})$ & $53.78-65.14$ \\
Alveolar ventilation rate $\left(1 \mathrm{~h}^{-1}\right)^{\mathrm{a}}$ & $286.21-330.10$ \\
Cardiac output $\left(^{-1}\right)^{\mathrm{a}}$ & $286.21-330.10$ \\
Organ volumes $(1)^{\mathrm{a}}$ & \\
Lung & $1.24-1.50$ \\
Fat & $12.62-15.29$ \\
Richly perfused tissues & $1.99-2.41$ \\
Slowly perfused tissues & $36.25-43.91$ \\
Liver & $1.40-1.69$ \\
Blood flow rates $\left(1 \mathrm{~h}^{-1}\right)^{\mathrm{a}}$ & \\
Fat & $14.31-16.51$ \\
Richly perfused tissues & $145.97-168.35$ \\
Slowly perfused tissues & $54.38-62.72$ \\
Liver & $71.55-82.53$ \\
Partition coefficients & \\
Blood/air & 590 \\
Lung/blood & 1.37 \\
Fat/blood & 189.35 \\
Richly perfused tissues/blood & 12.47 \\
Slowly perfused tissues/blood & 7.36 \\
Liver/blood & 10.15 \\
Metabolic constants & \\
Maximum reaction rate in lung $\left(\mathrm{mg} \mathrm{h}^{-1}\right)$ & $0.104-0.119$ \\
Maximum reaction rate in liver $\left(\mathrm{mg} \mathrm{h}^{-1}\right)$ & $265.70-304.36$ \\
Michaelis constant of lung $\left(\mathrm{mg} \mathrm{l}^{-1}\right)$ & 0.06 \\
Michaelis constant of liver $\left(\mathrm{mg} \mathrm{l}^{-1}\right)$ & 1.39 \\
\hline
\end{tabular}

a Adopted from ICRP (2003).

b Predicted values (Poulin and Krishnan, 1995; Poulin and Theil, 2002).

c Extrapolated values (Wiersma and Roth, 1983).

mixtures (gasoline) in human. These models integrate the physiologic, anatomic and biochemical characteristics of the intact body combined with pharmacodynamic (PD)based dose-response models in assessing chemical exposure risks. Lewtas et al. (1997) and Peluso et al. (2001) demonstrated that human exposed to $\mathrm{B}[a] \mathrm{P}$ via inhalation route shows a non-linear relationship between levels of external exposure and DNA adducts. Thyssen et al. (1981) and Heinrich et al. (1994) pointed out that the

Table 4

Modifying factors of $\mathrm{B}[a] \mathrm{P}$

\begin{tabular}{lll}
\hline Modifying factor & Range of $\mathrm{B}[\mathrm{a}] \mathrm{P}$ value & This study \\
\hline Interspecies extrapolation $\left(\mathrm{MF}_{1}\right)$ & $\leq 1-10$ & $5^{\mathrm{a}}$ \\
Intraspecies variability $\left(\mathrm{MF}_{2}\right)$ & $1-10$ & $10^{\mathrm{a}}$ \\
Database adequacy $\left(\mathrm{MF}_{3}\right)$ & $1-2$ (high) & $7^{\mathrm{b}}$ \\
& $3-7$ (medium) & \\
Malignancy $\left(\mathrm{MF}_{4}\right)$ & $8-10$ (low) & $5^{\mathrm{b}}$ \\
Genotoxicity $\left(\mathrm{MF}_{5}\right)$ & $3-10$ & $5^{\mathrm{a}}$ \\
\hline
\end{tabular}

${ }^{a}$ Adapted from Fitzgerald et al. (2004).

b Estimated values (Thyssen et al., 1981; RIVM, 1989; Culp et al., 1998). 
dose-response relationships of $\mathrm{B}[a] \mathrm{P}$-induced tumors in animal inhalation experiments are mostly nonlinear with an upward rise at high doses. The existing epidemiological and animal experimental data that accepted by analytical techniques were chosen for health risk assessment practices based on the availability of reasonable amounts of suitable information as the primary consideration. In this present study, we employed a HRT model to simulate deposition dynamics of PMs in lung regions associated with a PBPK/PD model to estimate PAHs exposure risk in temples.

The objectives of this study are threefold: (1) to estimate the airborne PMs mass concentrations, size distribution and mass lung/indoor (L/I) ratio for different HRT regions, (2) to estimate the concentration-time profiles of carcinogenic PAHs in human tissues, and (3) to conduct a mechanistic-based cancer risk assessment for carcinogenic PAHs during external/internal exposures in heavy incense burning temples.

\section{Materials and methods}

\subsection{Quantification of reported PM and PAH data}

Thanks to Fang et al. (2002) and Lin et al. (2002) who have provided the valuable data related to existed airborne PMs and PAHs in Taiwanese temples. Fang et al. (2002) selected a famous Taiwanese temple Tzu Yun Yen located in Ching Shui town in central Taiwan as the study site. The sampling time was from 9:00 a.m. to 7:00 p.m. on a daily basis and sampling periods were from August 2001 to January 2002 in that the particle size-dependent concentrations for incense burning were analyzed. Lin et al. (2002) selected a Taiwanese temple located in the suburban area of Tainan city in southern Taiwan. Sampling was conducted from 9:00 a.m. to 5:00 p.m. and from 9:00 a.m. to 9:00 a.m. the next day, respectively, for 3 sequential days during March 1996 in that individual PAH (particulate+gas phase) concentrations were analyzed. We reanalyze the published data to estimate the fitted distributions of PM and PAH concentrations of indoor air in temples by Kolmogorov-Smirnov (K-S) statistics to optimize the goodness-of-fit distributions of observed data.

The potency equivalence factor (PEF) scheme (Table 1) was used to calculate the $\mathrm{B}[a] \mathrm{P}$ equivalent concentration $\left(\mathrm{B}[a] \mathrm{P}_{\mathrm{eq}}\right)$ of the individual $\mathrm{PAH}$, whereas the carcinogenic potency of PAHs was estimated by summing each individual $\mathrm{B}[a] \mathrm{P}_{\text {eq. }}$. The PEF approach is based on the following key assumptions: (1) the relative potency of PAHs in animal models is the same or similar to that of the same compounds in humans; (2) the risk estimates of individual PAH are additive; (3) there is no interaction between individual PAH or between PAHs and other compounds at

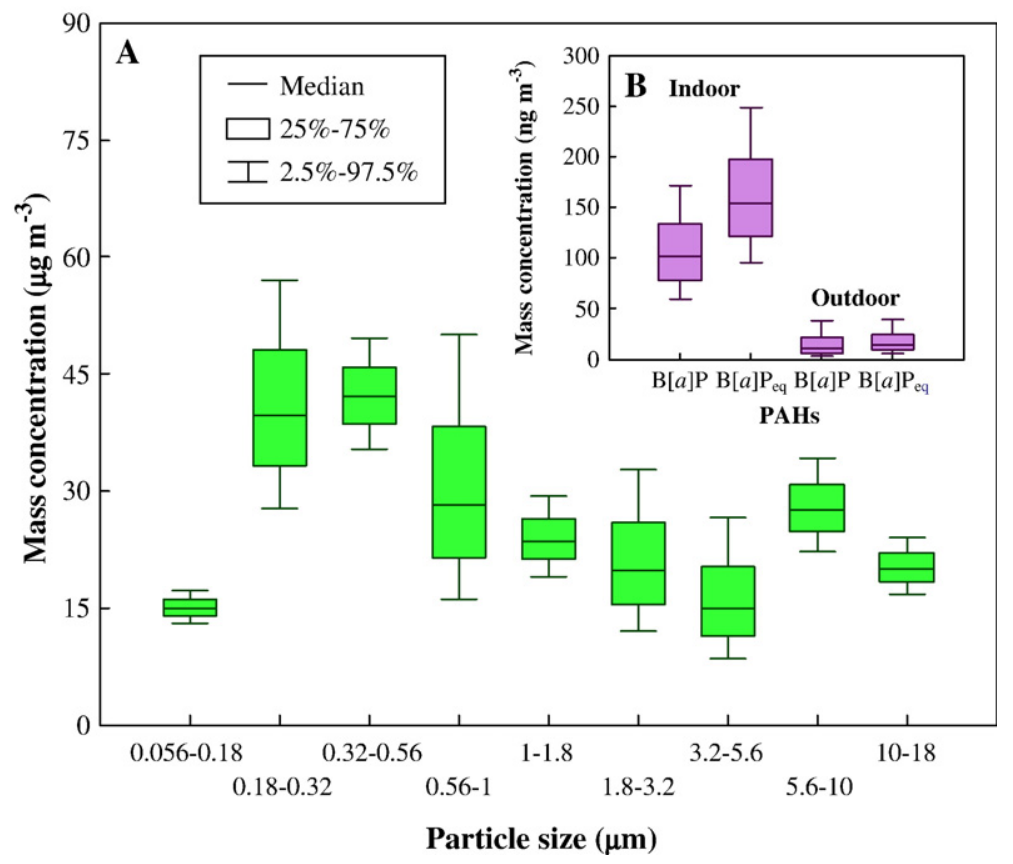

Fig. 2. Box and whisker plots of (A) mass concentration of airborne $\mathrm{PMs}$ for different size ranges in the temple and (B) $\mathrm{B}[a] \mathrm{P}-$ and $\mathrm{B}[a] \mathrm{P}_{\mathrm{eq}}$-based concentrations in indoor/outdoor of the temple. 
any dose level; and (4) PAHs ranking at levels used in animal studies is maintained at ambient exposure levels (Pufulete et al., 2004). To quantify uncertainty of data, a Monte Carlo simulation was performed with 5000 iterations (stability condition) to obtain the $95 \%$ confidence interval (CI) for PM and PAH concentrations. The Monte Carlo simulation was implemented by using the Crystal Ball software (Version 2000.2, Decisioneering, Inc., Denver, CO, USA). We used the 97.5th percentile as the model input concentration based on a conservative assumption for the protection of human health.

\subsection{Mechanistic human exposure models}

Mechanistic exposure models provide a powerful tool for the understanding and quantification of the relationship between exposure to a xenobiotic and tissue dosimetry. These models describe the processes of transport and kinetic and take explicit account of the physiological characteristics of the biological system in the species under investigation (Georgopoulos et al., 1997; Lazaridis et al., 2001).

\subsubsection{HRT model}

We used a HRT model to simulate the dynamics of respirable PM in human airways. The HRT model uses five compartments to represent respiratory tract (ICRP, 1994): (1) the nasal passage (ET 1$)$, consisting the anterior nose and the posterior nasal passages; (2) pharynx $\left(\mathrm{ET}_{2}\right)$, consisting larynx and mouth; (3) the bronchial region (BB), consisting the airway from trachea, main bronchi and intrapulmonary bronchi; (4) the bronchiolar region (bb), consisting the bronchioles and terminal bronchioles; and (5) alveolar-interstitial region (AI), consisting the airway from respiratory bronchioli through alveolar sacs. Chen et al. (2004) and Liao and Luo (2005) have comprehensively described the HRT model framework and the essential model parameters that characterizing the model structure and function.

\subsubsection{PBPK model}

For simulating the inhalation pharmacokinetics of $\mathrm{PAH}$, we used a basic human compartment structure that has been previously used in many PBPK models (Andersen et al., 1987; Mielke et al., 2005). The tissue compartments included in the model were: alveolus, lung, richly perfused tissues (brain, gut, kidney, spleen and heart), fat, slowly perfused tissues (bone, muscle and skin) and liver. Each tissue compartment was interconnected by arterial and venous blood (Fig. 1). The mathematical descriptions of pharmacokinetic processes employed in the PBPK model were provided in Table 2. The physiological and biochemical parameters were listed in Table 3 . The tissue/blood partition coefficients were calculated based on published data (Poulin and Krishnan, 1995; Poulin and Theil, 2002). The metabolic constants were determined by using the allometric scaling for interspecies extrapolation (Ramsey and Andersen, 1984). We employed the MATLAB ${ }^{\circledR}$ software (The Mathworks Inc., MA, USA) to perform the PBPK model simulations.

\subsection{Dose-response analysis}

Epidemiologically based dose-response data had been used to describe the relation between DNA adducts frequency $\left(\mathrm{DA}_{\mathrm{f}}\right)$ ratios and external $\mathrm{B}[a] \mathrm{P}$ concentrations in work environments in that the dose-response curve for DNA adducts was estimated in blood cells (Peluso et al., 2001). $\mathrm{DA}_{\mathrm{f}}$ could be defined as mean
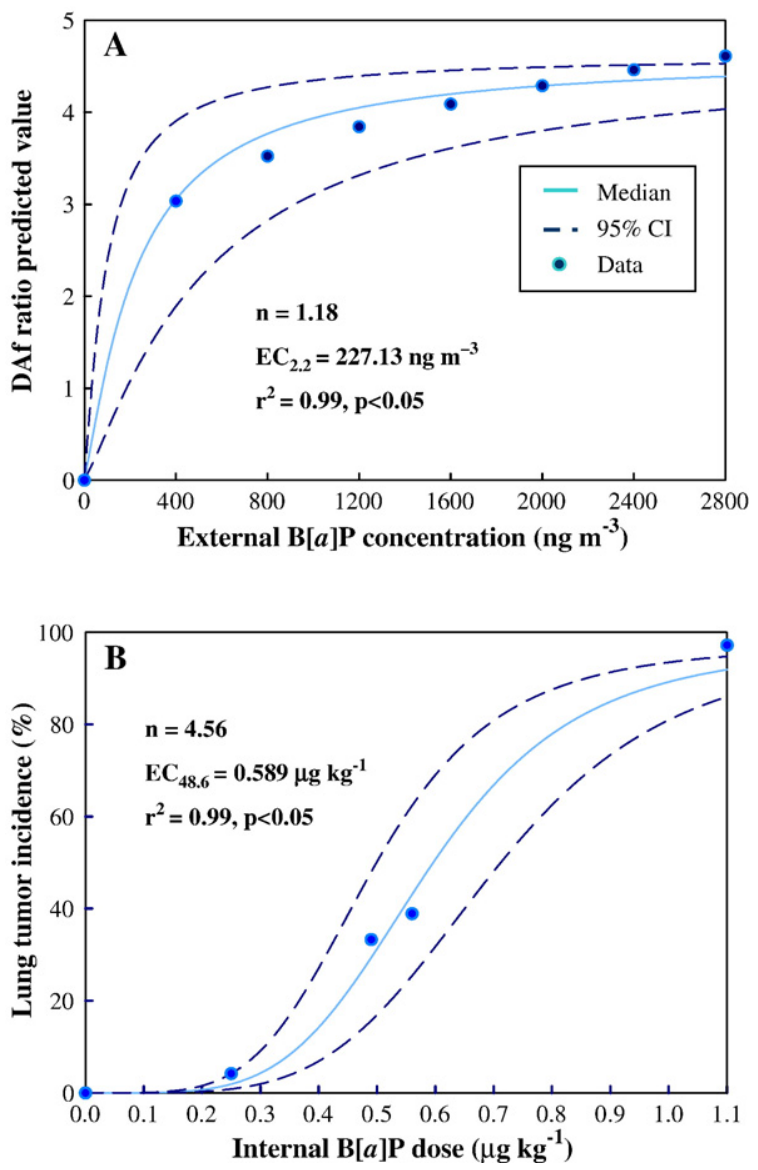

Fig. 3. Reconstructed dose-response profiles optimal fitted by a three parameters Hill equation model with $95 \%$ confidence interval: $(A)$ the relation between $\mathrm{DA}_{\mathrm{f}}$ ratios and external $\mathrm{B}[a] \mathrm{P}$ concentrations and $(\mathrm{B})$ the relation between lung tumor incidences and internal $\mathrm{B}[a] \mathrm{P}$ doses. 
DNA adduct levels of PAH-exposed workers over mean DNA adduct levels of referents (Peluso et al., 2001).

Animal experiment data had been used to estimate a unit risk for $\mathrm{B}[a] \mathrm{P}$ where 72 female Wistar rats were exposed to a coal tar/pitch aerosol containing either 20 or $46 \mu \mathrm{g} \mathrm{m}^{-3} \mathrm{~B}$ $[a] \mathrm{P}$ for $17 \mathrm{~h} \mathrm{day}^{-1}, 5$ days week $^{-1}$ for 10 or 20 months followed by a clean air period of up to 20 or 10 months, resulting in the corresponding lung tumor responses, $0 \%$, $4.2 \%, 33.3 \%, 38.9 \%$ and $97.2 \%$ (Heinrich et al., 1994).

We used a three-parameter Hill equation model to optimal fit epidemiological and animal experimental data to reconstruct dose-response profiles taking into accounting the effects to human health from DNA adducts formation and lung tumor occurrence. Hill equation model captures the relation between external concentration/ internal dose and effect as

$E=\frac{E_{\max } \times C^{n}}{E C_{50}^{n}+C^{n}}$

where $C$ is the external concentration/internal dose, $E_{\max }$ is the maximum effect, $\mathrm{EC}_{50}$ is the external concentration/

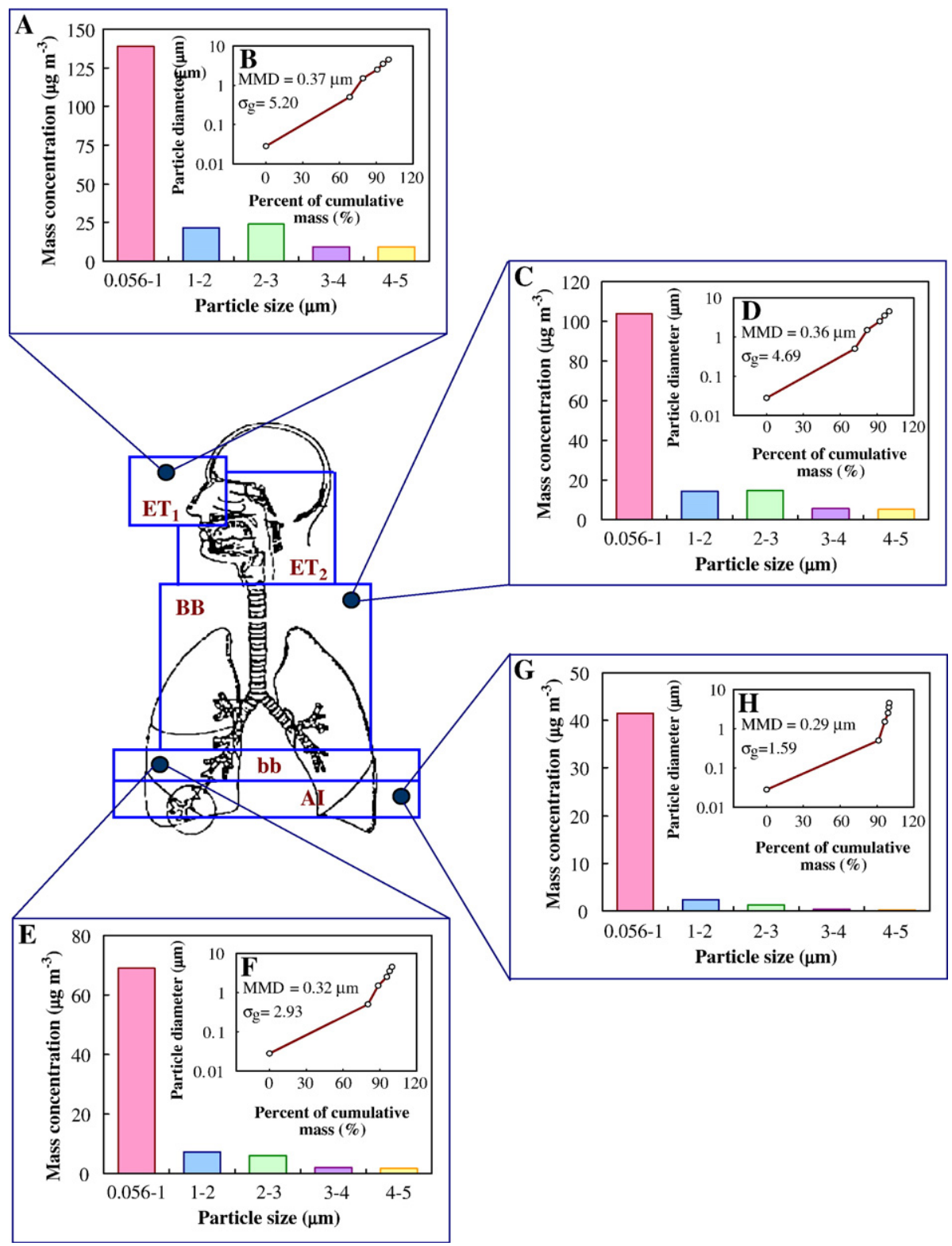

Fig. 4. Concentration distribution and size distribution patterns of PMs in different HRT regions: (A, B) ET1, (C, D) BB, (E, F) bb and (G, H) AI. 
internal dose giving half-maximum effect and $n$ is the Hill coefficient determine the overall shape of the curve.

The use of modifying factors (MFs) to address differences in pharmacodynamics across species was conceptually similar to approach used by USEPA to develop RfDs. The MFs accounted for interspecies extrapolation, intraspecies variability, the quality of data set as a whole, the ability of the compound to induce malignant tumors and the genotoxicity of the compound in question (NHMRC, 1999). Table 4 lists the numerical range of the MFs established for $\mathrm{B}[a] \mathrm{P}$ (Fitzgerald et al., 2004). We adjusted effect dose in Hill model to obtain the doseresponse profile for human exposure analogously by using MFs,

$\mathrm{EC}_{\mathrm{a}}=\frac{\mathrm{EC}}{\mathrm{MF}_{1} \times \mathrm{MF}_{2} \times \mathrm{MF}_{3} \times \mathrm{MF}_{4} \times \mathrm{MF}_{5}}$

where $\mathrm{EC}_{\mathrm{a}}$ is adjusted effect dose, $\mathrm{EC}$ is effect dose estimated from Hill equation, $\mathrm{MF}_{1}$ is modifying factor for interspecies extrapolation, $\mathrm{MF}_{2}$ is modifying factor for intraspecies variability, $\mathrm{MF}_{3}$ is modifying factor for database adequacy, $\mathrm{MF}_{4}$ is modifying factor for malignancy and $\mathrm{MF}_{5}$ is modifying factor for genotoxicity.

\subsection{Risk characterization}

Risk characterization is the component of the risk assessment that quantifies the magnitude of individual risk. We combined the exposure analysis with the analysis of biological effects expected at various concentrations/ doses to calculate individual risk. We employed the joint probability function described the probability of an ex-

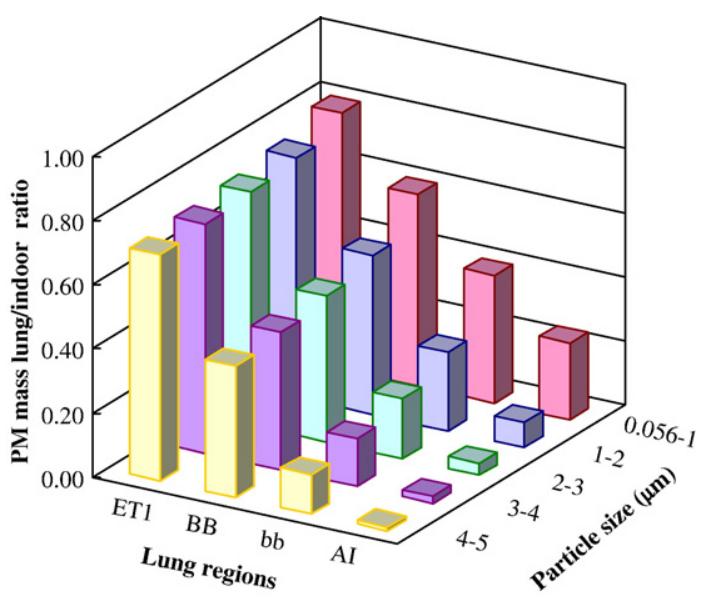

Fig. 5. Size-dependent lung/indoor ratios of PMs in different HRT regions during incense burning period inside the temple.
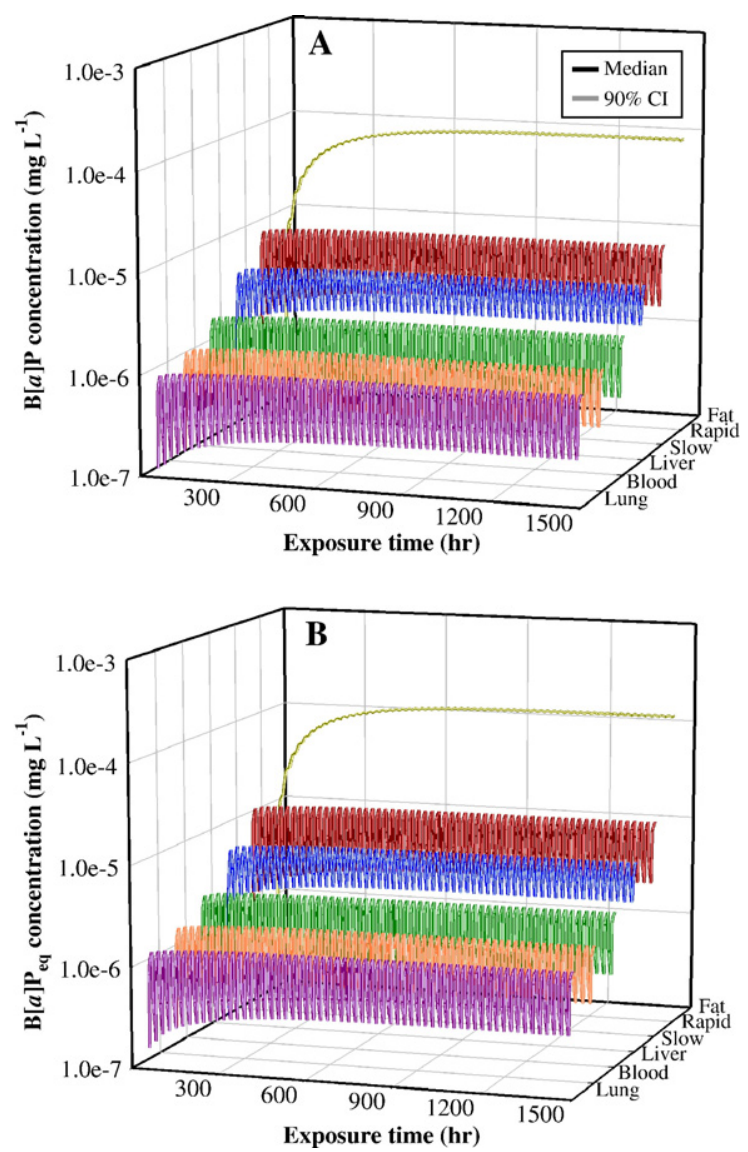

Fig. 6. Simulated time-course concentrations of (A) $\mathrm{B}[a] \mathrm{P}$ and (B) $\mathrm{B}[a] \mathrm{P}_{\mathrm{eq}}$ in human tissues.

ternal concentration and internal dose exceeding a concentration/dose that resulted in particular magnitude of biological effect,

$R(C)=P(C) \times P(E \mid C)$

where $R(C)$ is the risk at a specific concentration or dose $C, P(C)$ is the probability of external concentration or internal having tissue dose $C$ and $P(E \mid C)$ is the conditional probability of the adverse effect, given external concentration or internal having tissue dose $C$.

\section{Results}

\subsection{PM and PAH concentrations in temples}

The predicted indoor PM concentrations in temples are presented in Fig. 2A, whereas the predicted indoor/ outdoor PAH concentrations of temples are presented in Fig. 2B. It shows that the two peaks of the average mass distributions occur at $0.32-0.56 \mu \mathrm{m}$ and $5.6-10 \mu \mathrm{m}$, 
respectively. The median $\mathrm{PM}_{1}$ and $\mathrm{PM}_{10}$ concentrations are estimated to be 125.11 and $211.36 \mu \mathrm{g} \mathrm{m}^{-3}$, respectively. Results indicate that fine particles are the major contributions of PM concentrations in temples. The median $\mathrm{B}[a] \mathrm{P}$-and $\mathrm{B}[a] \mathrm{P}_{\mathrm{eq}}$-based concentrations in temples are estimated to be 101.8 and 153.61 , and 10.22 and $14.31 \mathrm{ng} \mathrm{m}^{-3}$ in indoor and outdoor, respectively. Our results suggest that temple is a significant source of PAHs.

\subsection{Health effect assessment}

We reconstruct the dose-response models for external and internal $\mathrm{B}[a] \mathrm{P}$ levels by fitting a Hill equation model to the $\mathrm{B}[a] \mathrm{P}$ data of DNA adducts and lung tumor from Peluso et al. (2001) and Heinrich et al. (1994), respectively (Fig. 3). The external concentration and internal dose of half-maximum response of $\mathrm{B}[a] \mathrm{P}$ are estimated to be $227.13 \mathrm{ng} \mathrm{m}^{-3}$ (95\% CI: $\left.94.78-544.28 \mathrm{\mu g} \mathrm{m}^{-3}\right)$ and $0.589 \mu \mathrm{g} \mathrm{kg}^{-1}$ (95\% CI: $0.493-0.703 \mu \mathrm{g} \mathrm{kg}^{-1}$ ), respectively (Fig. 3A and B), whereas the Hill coefficients estimated from epidemiological data and animal experimental data are 1.18 and 4.56, respectively (Fig. 3A and B). Results indicate the situation of $\mathrm{B}[a] \mathrm{P}$ binding to receptors (DNA or lung cells) is significant, resulting from the doseresponse relationships for human exposure to $\mathrm{B}[a] \mathrm{P}$.

\subsection{Cumulative concentration in human tissue}

Fig. 4 shows the mass concentration and size distribution patterns of PM present in each of four regions of the HRT. Because the airborne PM concentrations within the four regions reach the steady state in $5-10 \mathrm{~s}$ for all the size ranges, it is more important to understand the PM concentration, $\mathrm{L} / \mathrm{I}$ ratio and size distribution pattern than the dynamics of airborne PM in HRT. A comparison of the $\mathrm{PM}$ concentrations in four regions indicates that the PM concentrations are lower in the deeper region (AI region), suggesting that the deposition effect makes the PM no longer airborne especially in larger size ranges. The mass median diameter (MMD) is estimated to be $0.37,0.36$, 0.32 and $0.29 \mu \mathrm{m}$, respectively, in $\mathrm{ET}_{1}, \mathrm{BB}, \mathrm{bb}$ and $\mathrm{AI}$ in
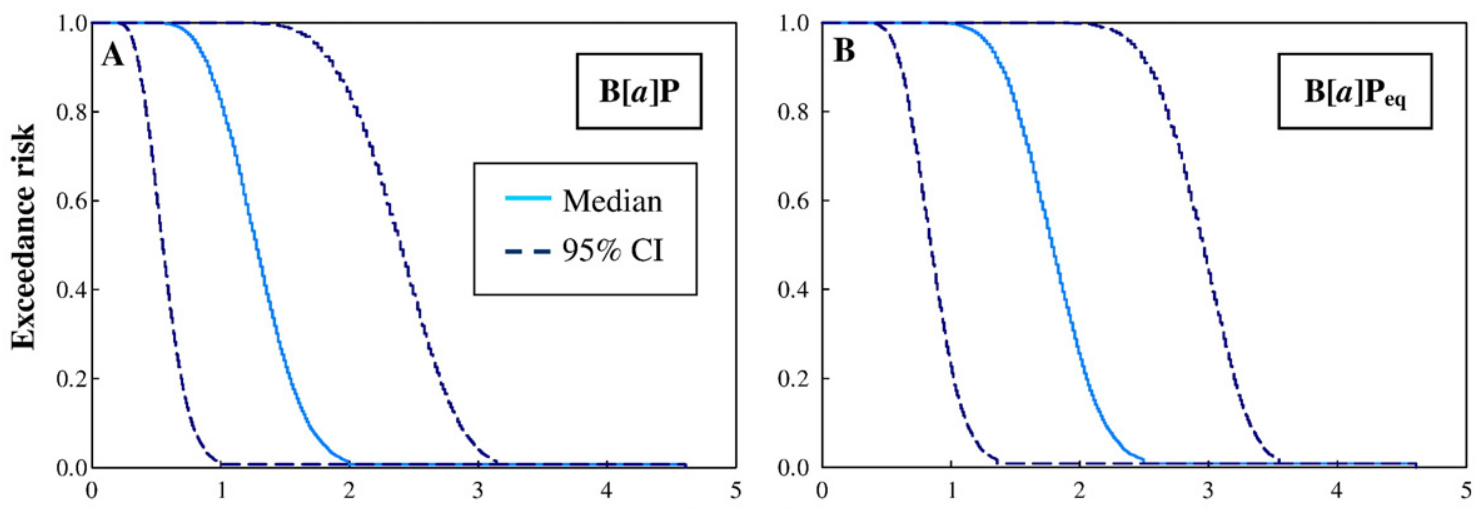

$\mathrm{DA}_{\mathrm{f}}$ ratio predicted value
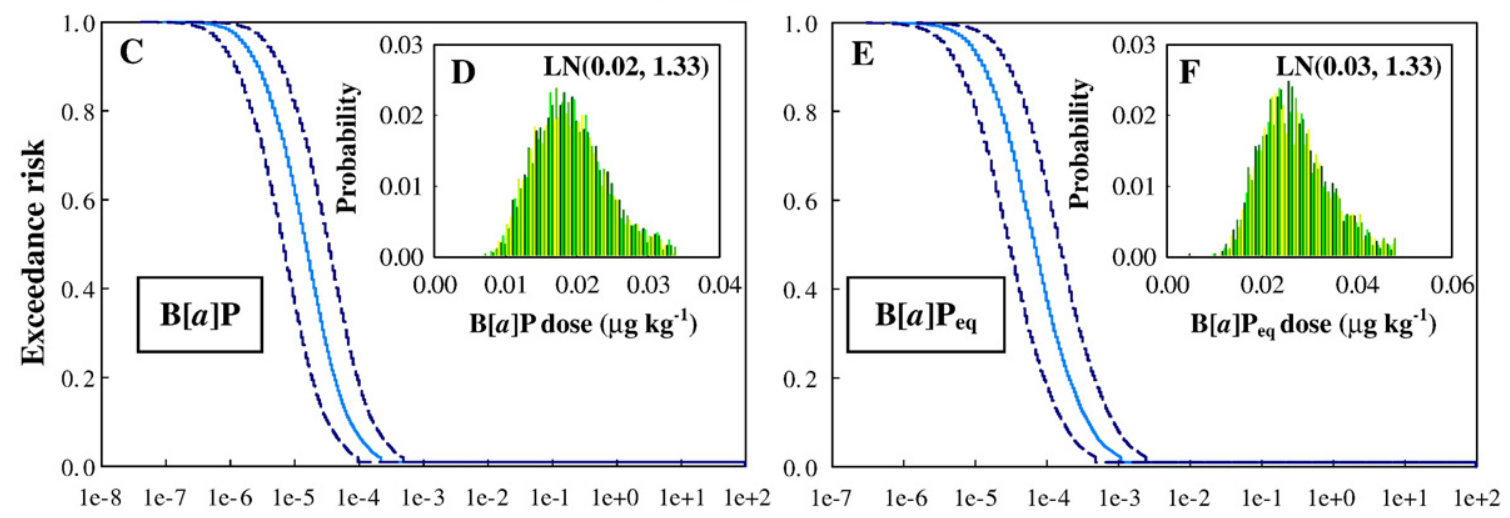

Lung tumor incidence $(\%)$

Fig. 7. Estimated exceedance risk curves with $95 \%$ confidence interval for $\mathrm{B}[a] \mathrm{P}-$ and $\mathrm{B}[a] \mathrm{P}_{\text {eq }}$-based $(\mathrm{A}, \mathrm{B})$ external concentrations and $(\mathrm{C}, \mathrm{E})$ internal doses along with probabilistic density functions $(\mathrm{D}, \mathrm{F})$. 
that $\mathrm{AI}$ region has lower geometric mean deviations than that of other HRT regions, indicating that fine particles are apt to exist in the AI region (Fig. 4B,D,E,F). The ET region has higher $\mathrm{L} / \mathrm{I}$ ratio $(0.71-0.79)$ than that of the $\mathrm{BB}$ $(0.40-0.59)$, bb (0.12-0.39) and AI (0.01-0.23) regions, whereas the distribution patterns of the size-dependent L/I ratios decreasing with the size range are similar in four regions of the HRT (Fig. 5).

Fig. 6 shows the simulated time-course concentrations of $\mathrm{B}[a] \mathrm{P}$ and $\mathrm{B}[a] \mathrm{P}_{\mathrm{eq}}$ in human tissues following inhalation exposure. Peak exposure $\left(12 \mathrm{~h}\right.$ day $^{-1}$ on 60 consecutive days for temples worker) is clearly reflected by fluctuating concentrations in human tissues which increase with duration of exposure and reach steady state. The highest $\mathrm{B}[a] \mathrm{P}$ and $\mathrm{B}[a] \mathrm{P}_{\mathrm{eq}}$ concentrations are observed in fat, followed by rapidly perfused tissues, slowly perfused tissues, liver, blood and lung. The median $\mathrm{B}[a] \mathrm{P}$ and $\mathrm{B}[a] \mathrm{P}_{\text {eq }}$ steady-state concentration ratios of tissue/human are $0.03,0.04,0.06$, 0.16, 0.27 and 4.07 for lung, blood, liver, slowly perfused tissues, rapidly perfused tissues and fat, respectively. Results show that $\mathrm{B}[a] \mathrm{P}$ is the highly lipophilic compound and accumulates easily in human. Moreover, the fat tissue has the highest concentration, whereas the lung and liver tissues experience the lowest concentration that are attributable to the properties such as lipophilicity and metabolic clearance of tissues. The evaluation of the uncertainty for the inhalation of PAHs also implicates that the human pharmacokinetic variability may not attribute to the differences in physiological parameters.

\subsection{Human health risk assessment}

The simple probability statements can be plotted as points on a graph of probability of exceedance vs. effect (Fig. 7). There is a $50 \%$ probability (risk $=0.5$ ) of exceeding the $\mathrm{DA}_{\mathrm{f}}$ ratio of $1.28(95 \% \mathrm{CI}$ : $0.55-2.40)$ and 1.78 (95\% CI: 0.84-2.95) for external exposure of $\mathrm{B}$ $[a] \mathrm{P}$ and $\mathrm{B}[a] \mathrm{P}_{\text {eq }}$, respectively (Fig. $7 \mathrm{~A}$ and $\mathrm{B}$ ). Furthermore, risk curves indicate that the probability that $10 \%$ or more of human (risk $=0.1$ ) affected by lung tumor is approximately $7.62 \times 10^{-5} \%\left(95 \%\right.$ CI: $3.39 \times 10^{-5}$ $\left.1.71 \times 10^{-4} \%\right)$ and $3.87 \times 10^{-4} \%$ (95\% CI: $1.72 \times 10^{-4}$ $8.69 \times 10^{-4} \%$ ) based on the internal exposure profiles (Fig. $7 \mathrm{D}$ and $\mathrm{F}$ ) of $\mathrm{B}[a] \mathrm{P}$ and $\mathrm{B}[a] \mathrm{P}_{\text {eq }}$, respectively (Fig. $7 \mathrm{C}$ and $\mathrm{E}$ ). Our analyses indicate that human exposure to $\mathrm{B}$ $[a] \mathrm{P}$ in temples may induce significant levels of DNA adducts and that promote lung tumor development.

\section{Discussion}

The carcinogenic risk assessment of PAH remains difficult, particularly due to the very high number of these compounds (in the hundreds) present in mixtures to which the general population may be exposed, as well as due to the possible contemporary presence of other risk factors and to possible synergistic and/or antagonistic effects. The choice of $\mathrm{B}[a] \mathrm{P}$ as the reference compound to develop the PEF is presently questioned (Goldstein, 2001). Due to the limited number of dose-response data on carcinogenicity and depending on the exposure route (intratracheal administration, intrapulmonary injection and so on), different PEFs can be obtained. For example, the PEF value used in this study for $\mathrm{DB}[a, h] \mathrm{A}$ is 1.0 , as given by Malcolm and Dobson, 1994. This value may underestimate the relevance of this compound, because other authors claim a PEF of 5.0 (Nisbet and LaGoy, 1992). It has also been noted that the $\mathrm{B}[a] \mathrm{P}_{\mathrm{eq}}$ concentrations used for this calculation represent an external exposure estimation of carcinogenic compounds and not the effective active concentration at the lung level.

Here we adopted the current National Air Quality Standard (NAQS) documented by Taiwan Government for $\mathrm{PM}_{10}$ serving as a reference value to evaluate the PMs concentrations existed in temples. On the other hand, the predicted $\mathrm{PM}_{1}$ concentration is found to exceed the $24 \mathrm{~h}$ average standard $\left(125 \mathrm{\mu g} \mathrm{m}^{-3}\right)$ during incense burning in the temple. In a comparison with the reference value suggested by NAQS that is aimed at ambient air rather than at indoor air, we suggest that most adverse health effects may relate to the fine PMs in temples. On the other hand, the target annual mean values of $\mathrm{B}[a] \mathrm{P}$ of 0.7 to $1.3 \mathrm{ng} \mathrm{m}^{-3}$ established by a few European countries (Ballesta et al., 1999), and the WHO risk estimate for PAHs in air based on lung cancer in coke-oven workers had led to a health-based guideline value of $0.1 \mathrm{ng} \mathrm{m}^{-3}$ $\mathrm{B}[a] \mathrm{P}$ for ambient air (WHO, 2000; Bostrom et al., 2002). The $\mathrm{B}[a] \mathrm{P}$ and $\mathrm{B}[a] \mathrm{P}_{\text {eq }}$-based concentrations in the temple are much higher than the reference/guideline value, suggesting that human PAHs exposure in the temple may result in the potential cancer risk. Therefore, it is important to identify individuals who are "at risk" of carcinogenic effects by PAHs exposure in the temple.

Recently, human health risk assessments have been frequently based on the biologically effective dose rather than the ambient exposure level (Andersen et al., 1987; Dennison et al., 2004). Taking physiological and biochemical characteristics into account in exposure models can provide true internal doses of chemicals that would correlate more accurately with toxicity in human than that developed solely on external exposure. Considering the prevalence of PAHs in environment and their known carcinogenic potential, it is noted that PBPK modeling work on this class of chemicals has been fairly limited. The following points may give the explanations: (1) $\mathrm{PAH}$ 
exposure often involves exposure to mixtures of PAHs and other chemicals; (2) exposures are typically to low levels of PAHs, exacerbating the difficulties associated with low-level extrapolation from high-level models; (3) at least some of the airborne chemical present is adsorbed to surfaces of particles, complicating the assumption of equilibrium between ambient concentrations and the concentration in lung blood; and (4) dermal exposure is also an important route of exposure (Reddy et al., 2005). However, combining physiologically based pharmacokinetic aspects with quality data can help us enhance exposure assessment for carcinogenic PAHs in heavy incense burning temples.

DNA adducts have been widely used to assess cancer risk for human exposures to carcinogenic PAHs (Kriek et al., 1998; Poirier, 2004; Vineis and Husgafvel-Pursiainen, 2005). Using the $\mathrm{DA}_{\mathrm{f}}$ ratio rather than the DNA adduct levels enable us to avoid large interlaboratory variability (Peluso et al., 2001). Because simulated B $[a] \mathrm{P}$ concentrations in the temples still is in the higher ranges, we do not assume that the dose-response curve is linear at low exposure concentrations. Moreover, taken together all the available in vitro/vivo and epidemiologic data, it can be concluded that it is possible to use DNA adduct data not only for exposure assessment, but also as a measure of human cancer risk. How to determine cross-species extrapolation in dose-response assessment is a crucial issue in health risk assessment. A more accurate and conservative extrapolation to the human airborne carcinogen exposures could be achieved by introducing the MFs. The adequacy of database factor $\left(\mathrm{MF}_{3}\right)$, comparing with the relevant inhalation studies by Thyssen et al. (1981) and RIVM (1989), is given a value of 7 to reflect a conservative viewpoint and medium degree of confidence. The malignancy factor $\left(\mathrm{MF}_{4}\right)$ is well established and together with the Thyssen et al. (1981) and Culp et al. (1998) bioassay study in which $\mathrm{B}[a] \mathrm{P}$-induced tumors in the nasal cavity, larynx, pharynx, esophagus, tongue and forestomach. The lungs were free of neoplastic growth, which engenders a proposed modifying factor of 5 . However, the suitability of published data for dose-response modeling is important and needs to be justified deliberately.

Mode-of-action of a compound has occasionally been considered in risk assessments, either to help in the determination of the particular carcinogenic effect seen in humans or to support the estimation of acceptable levels for human exposures (Clewell and Andersen, 2004). Information on the carcinogenic mode-of-action in each target tissue becomes more important. Mechanistic exposure models can provide a valuable insight that considers human variability for risk assessment. An arising of human variability is from a variety of sources, including different activity levels altering physiological parameters and metabolizing enzymes (Clark et al., 2004). We, however, believe that it would be interesting to explore mode-of-action information and human variability in the future studies.

In conclusion, we have demonstrated here the utilities and advantages of using physiologically based pharmacokinetic/pharmacodynamic modeling in human exposure and effect analyses from airborne PMs and carcinogenic PAHs present in heavy incense burning temples. We also use the uncertainty analysis to estimate the 97.5 th percentile of the distribution defined a reasonable maximum concentration, which is analogous to the reasonable maximum exposure commonly used in risk assessment. Furthermore, our study shows a mechanistic perspective based on the pollutant effects in human can promote health risk assessment for personal exposure to airborne PMs and carcinogenic PAHs in heavy incense burning temples. We believe that the results obtained in this study can provide a reference index as a human health exposure criterion in the near future for better indoor air quality management.

\section{References}

Andersen ME, Clewell HJ, Gargas HL, Smith FA, Reitz RH. Physiologically based pharmacokinetics and the risk assessment process for methylene chloride. Toxicol Appl Pharmacol 1987;87:185-205.

Armstrong B, Hutchinson E, Unwin J, Fletcher T. Lung cancer risk after exposure to polycyclic aromatic hydrocarbons: a review and meta-analysis. Environ Health Perspect 2004;112:970-8.

Ballesta PP, De Salgar E, Kotzias D. State of the art of the PAHs' analysis in ambient air. Fresenius Environ Bull 1999;8:499-505.

Boffetta P, Jourenkova N, Gustavsson P. Cancer risk from occupational and environmental exposure to polycyclic aromatic hydrocarbons. Cancer Causes Control 1997;8:444-72.

Bostrom CE, Gerde P, Hanberg A, Jernstrom B, Johansson C, Kyrklund $\mathrm{T}$, et al. Cancer risk assessment, indicators, and guidelines for polycyclic aromatic hydrocarbons in the ambient air. Environ Health Perspect 2002;110:451-89.

Chen HW. Environmental exposure to nitrated polycyclic aromatic hydrocarbons in the Taiwanese temple. Bull Environ Contam Toxicol 2005;74:399-406.

Chen JW, Liao CM, Chen SC. Compartmental human respiratory tract modeling of airborne dust exposure from feeding in swine buildings. J Air Waste Manage Assoc 2004;54:331-41.

Chuang HC, 2005. Effects of temple particles on inflammatory reaction and endothelial dysfunction by human coronary artery endothelial cell. MS Thesis, National Taiwan University, Taipei, Taiwan ROC.

Clark LH, Setzer RW, Barton HA. Framework for evaluation of physiologically-based pharmacokinetic models for use in safety or risk assessment. Risk Anal 2004;24:1697-717.

Clewell HJ, Andersen ME. Applying mode-of-action and pharmacokinetic considerations in contemporary cancer risk assessments: an example with trichloroethylene. Crit Rev Toxicol 2004;34:385-445.

Clewell HJ, Gentry PR, Kester JE, Andersen ME. Evaluation of physiologically based pharmacokinetic models in risk assessment: an example with perchloroethylene. Crit Rev Toxicol 2005;35:413-33. 
Culp SJ, Gaylor DW, Winslow GS, Goldstein LS, Beland FA. A comparison of the tumors induced by coal tar and benzo $(a)$ pyrene in a 2-year bioassay. Carcinogenesis 1998;19:117-24.

Dennison JE, Andersen ME, Clewell HJ, Yang RSH. Development of a physiologically based pharmacokinetic model for volatile fractions of gasoline using chemical lumping analysis. Environ Sci Technol 2004;38:5674-81.

Fang GC, Chu CC, Wu YS, Fu PPC. Emission characters of particulate concentrations and dry deposition studies for incense burning at a Taiwanese temple. Toxicol Ind Health 2002;18:183-90.

Fang GC, Chang CN, Chu CC, Wu YS, Fu PPC, Chang SC, et al. Fine (PM2.5), coarse (PM2.5-10), and metallic elements of suspended particulates for incense burning at Tzu Yun Yen temple in central Taiwan. Chemosphere 2003;51:983-91.

Fitzgerald DJ, Robinson NI, Pester BA. Application of benzo( $a$ )pyrene end coal tar tumor dose-response date to a modified benchmark dose method of guideline development. Environ Health Perspect 2004;112:1341-6.

Georgopoulos PG, Walia A, Roy A, Lioy PJ. Integrated exposure and nose modeling and analysis system .1. Formulation and testing of microenvironmental and pharmacokinetic components. Environ Sci Technol 1997;31:17-27.

Goldstein LS. To BaP or not to BaP? That is the question. Environ Health Perspect 2001;109:A356-7.

Heinrich U, Roller M, Pott F. Estimation of a lifetime unit lung cancer risk for benzo $[a]$ pyrene based on tumour rates in rats exposed to coal tar/pitch condensation aerosol. Toxicol Lett 1994;72:155-61.

Ho CK, Tseng WR, Yang CY. Adverse respiratory and irritant health effects in temple workers in Taiwan. J Toxicol Environ Health Part A 2005;68:1465-70.

Ho SSH, Yu JZ. Concentrations of formaldehyde and other carbonyls in environments affected by incense burning. J Environ Monit 2002;4:728-33.

ICRP. Human respiratory tract model for radiological protection, a report of a task group of the international commission on radiological protection, ICRP Publication No. 66. New York: Pergamon Press; 1994.

ICRP. Basic anatomical and physiological data for use in radiological protection: reference values, ICRP Publication No. 89. New York: Pergamon Press; 2003.

Kriek E, Rojas M, Alexandrov K, Bartsch H. Polycyclic aromatic hydrocarbon-DNA adducts in humans: relevance as biomarkers for exposure and cancer risk. Mut Res Fundam Mol Mech Mutagen 1998;400:215-31.

Lazaridis M, Broday DM, Hov O, Georgopoulos PG. Integrated exposure and dose modeling and analysis system: 3. Deposition of inhaled particles in the human respiratory tract. Environ Sci Technol 2001;35:3727-34.

Lee SC, Wang B. Characteristics of emissions of air pollutants from burning of incense in a large environmental chamber. Atmos Environ 2004;38:941-51.

Lewtas J, Walsh D, Williams R, Dobias L. Air pollution exposure DNA adduct dosimetry in humans and rodents: evidence for nonlinearity at high doses. Mut Res Fundam Mol Mech Mutagen 1997;378:51-63.

Li DH, Firozi PF, Wang LE, Bosken CH, Spitz MR, Hong WK, et al. Sensitivity to DNA damage induced by benzo $(a)$ pyrene diol epoxide and risk of lung cancer: a case-control analysis. Cancer Res 2001;61:1445-50.

Liao CM, Luo WC. Use of temporal/seasonal- and size-dependent bioaerosol data to characterize the contribution of outdoor fungi to residential exposures. Sci Total Environ 2005;347:78-97.
Lin TC, Chang FH, Hsieh JH, Chao HR, Chao MR. Characteristics of polycyclic aromatic hydrocarbons and total suspended particulate in indoor and outdoor atmosphere of a Taiwanese temple. J Hazard Mater 2002;95:1-12.

Lung SCC, Kao MC, Hu SC. Contribution of incense burning to indoor $\mathrm{PM}_{10}$ and particle-bound polycyclic aromatic hydrocarbons under two ventilation conditions. Indoor Air 2003;13: 194-9.

Malcolm HM, Dobson S. The calculation of an environmental assessment level (EAL) for atmospheric PAHs using relative potencies. London, UK: Department of the Environment; 1994. p. 34-46.

Mielke H, Gundert A, Abraham K, Gundert-Remy U. Acute inhalative exposure assessment: derivation of guideline levels with special regard to sensitive subpopulations and time scaling. Toxicology $2005 ; 214: 256-67$.

NHMRC. 1999. Toxicity Assessment for Carcinogenic Soil Contaminants. Canberra, Australia: National Health and Medical Research Council. Available: http://www.health.gov.au:80/nhmrc/ publications/synopses/eh21syn.htm.

Nisbet ICT, LaGoy PK. Toxic equivalency factors (TEFs) for polycyclic aromaic hydrocarbons (PAHs). Regul Toxicol Pharmacol 1992;16:290-300.

Peluso M, Ceppi M, Munnia A, Puntoni R, Parodi S. Analysis of 13 P-32-DNA postlabeling studies on occupational cohorts exposed to air pollution. Am J Epidemiol 2001;153:546-58.

Poirier MC. Chemical-induced DNA damage and human cancer risk. Nat Rev Cancer 2004;4:630-7.

Pope CA, Burnett RT, Thun MJ, Calle EE, Krewski D, Ito K, et al. Lung cancer, cardiopulmonary mortality, and long-term exposure to fine particulate air pollution. J Am Med Assoc 2002;287: $1132-41$.

Pope CA, Burnett RT, Thurston GD, Thun MJ, Calle EE, Krewski $\mathrm{D}$, et al. Cardiovascular mortality and long-term exposure to particulate air pollution - epidemiological evidence of general pathophysiological pathways of disease. Circulation 2004;109: $71-7$.

Poulin P, Krishnan K. A biologically-based algorithm for predicting human tissue: blood partition coefficients of organic chemicals. Hum Exp Toxic 1995;14:273-80.

Poulin P, Theil FP. Prediction of pharmacokinetics prior to in vivo studies: 1. Mechanism-based prediction of volume of distribution. J Pharm Sci 2002;91:129-56.

Pufulete M, Battershill J, Boobis A, Fielder R. Approaches to carcinogenic risk assessment for polycyclic aromatic hydrocarbons: a UK perspective. Regul Toxicol Pharmacol 2004;40:54-66.

Ramsey JC, Andersen ME. A physiologically based description of the inhalation pharmacokinetics of styrene in rats and humans. Toxicol Appl Pharmacol 1984;73:159-75.

Reddy MB, Yang RSH, Clewell HJ, Andersen ME. Physiologically Based Pharmacokinetic Modeling: Science and Applications. New York: Wiley; 2005.

RIVM. Integrated Criteria Document PAHs. 758474011:1-199. Bilthoven: National Institute of Public Health and Environmental Protection; 1989.

Smith LE, Denissenko MF, Bennett WP, Li HY, Amin S, Tang MS, et al. Targeting of lung cancer mutational hotspots by polycyclic aromatic hydrocarbons. J Nat Cancer Inst 2000;92:803-11.

Sun Q, Wang A, Jin X, Natanzon A, Duquaine D, Brook RD, et al. Long-term air pollution exposure and acceleration of atherosclerosis and vascular inflammation in an animal model. J Am Med Assoc 2005;294:3003-10. 
Thyssen J, Althoff J, Kimmerle G, Mohr U. Inhalation studies with benzo [a]pyrene in Syrian golden hamsters. J Nat Cancer Inst 1981;66: 575-7.

Vineis P, Husgafvel-Pursiainen K. Air pollution and cancer: biomarker studies in human populations. Carcinogenesis 2005;26: $1846-55$.

WHO. Air quality guidelines for Europe. WHO regional publications, vol. 91. Copenhagen: WHO Regional Office for Europe; 2000.
Wiersma DA, Roth RA. The prediction of benzo $[a]$ pyrene clearance by rat liver and lung from enzyme kinetic data. Mol Pharmacol 1983;24: 300-8.

Yang HH, Jung RC, Wang YF, Hsieh LT. Polycyclic aromatic hydrocarbon emissions from joss paper furnaces. Atmos Environ 2005;39:3305-12. 